\title{
TRADEMARK INFRINGEMENTS IN THE DOMAIN “.CZ”
}

\section{Tomáš Gongol}

\section{Introduction}

This article deals with finding and evaluating the extent of trademark infringements in the field of domain ".cz" (further referred to as Czech domain). Not only in the Czech legal environment, the question of disputes between intellectual property rights (esp. trademarks) and domain names has traditionally been included in the interpretation of information technology law (Polčák et al., 2018; Lloyd, 2011) or internet law (Jansa et al., 2016; Edwards \& Waelde, 2009). Trademarks have a number of functions in the market economy that are described in a number of professional publications (e.g. Horáček et al., 2017) and also extended by follow-up judicial practice. The trademark is an important business identifier for entrepreneurs. It reinforces sales of goods and services on the market, therefore, the entrepreneurs invest considerable financial resources into promoting it (see, for example, Crass et al., 2019). Its basic function is to distinguish the products or services of one trader from the products and services of another and it protects consumers from misleading (Lukose, 2013). It is also an effective tool for providing information on the market (Griffiths, 2008; Burmann, 2017) and helps its owners to obtain and maintain a position in the competition (Slováková, 2006; Munková et. al., 2012). The trademark infringement that is left without an adequate response can lead to the reduction of its distinctive character, and ultimately to its demise. This is true not only in the material world, but also in the digital environment (see Merges et al., 2012). The use of the trademark as a domain name can have a negative impact not only on advertising, but also on the business strategy of its owner, so it is important to address the question of the actual state of its abuse. For such examination, it is necessary to use an interdisciplinary approach involving not only the area of the law but also of marketing, the economics of information, information technology, cybernetics and statistics. Thousands of disputes being resolved worldwide whether judicially or the alternate way suggest the extent of the conflict of trademarks vs. domain names. There has been an extensive publishing activity to this issue. It addresses both, the nature of dispute procedure, e.g., Gongol (2014), Pelikánová (2012), Jansa et al. (2016), Werra (2016), and analyses of specific disputes resolved this way, e.g., Bettinger (2005), Merges et al. (2012), Gongol (2013a). There also known more ways of trademark infringement on the Internet, part of which are the use of trademark as a keyword in the search engines (referred to by Gongol, 2013b; Janis \& Dinwoodie, 2007; Gielen, 2010; Senftleben, 2012; Oullette, 2014), in metadata of websites, e.g. auction portals (referred to by Otim \& Grover, 2010; Saunders \& BergerWalliser, 2011; Gongol, 2016). In this context, however, it is possible to ask several research questions that extend the explored region further and deepen the real condition in the Czech domain:

1. Is the phenomenon of the trademark infringement a rather minor issue, which concerns only a fraction of domain names and websites, or is it a widespread practice on the Internet?

2. Do domain names or websites that violate trademark rights share similar characters?

3. Is it possible to automate the process of searching for trademark infringements or is it possible to find general rules that can be a valuable help in this process?

To date, there is not known any relevant study that would have dealt with these issues more deeply and provided even an approximate quantification or methodology. Some of the sub-aspects are dealt with by the older study by Branthover (2002) that is focused on the 
results of the disputed proceedings, or the success of the complainant in the correlation with the selection of the court, which is further followed by a newer study focused on the forum selling by Klerman (2016). From newer works can be mentioned Visserse et al. (2015), which focuses on the analysis and detection of a narrower circuit called Parked domains. Similarly, a study focused on malware and phishing domains from Korczynski et al. (2017), which follows the previous analysis by Halvorson et. al. (2015). Analytic and statistical reports are also available at administrators of both national and generic domains. The basic statistic overview is also provided by the administrator of the Czech domain CZ.NIC. on its website. In order to be able to answer the above questions in general terms at least, it is necessary to link the results of the analysis of the decision-making practice given in the previous work of the author (Gongol, 2012) to the real situation on the Internet. It is necessary to examine the websites, their content and domain names and put them into correlation with existing trademarks. In this article the attention will be focused on the Czech domain, specifically on measuring the amount of trademark infringements in automotive industry in which a considerable amount of investments is carried out. The automotive sector is widely represented on the Internet. Therefore, the websites of automakers are often searched among the Czech population which in fact creates good conditions for research. In the automotive sector will be examined a series of characters that occur in cases of trademark infringements or, on the contrary, lead to confirmation that the website does not abuse a trademark.

\section{Methodology}

On the basis of the decision-making practice of the World Intellectual Property Organization (WIPO) and the Czech Arbitration Court attached to the Economic Chamber of the Czech Republic and the Agricultural Chamber of the Czech Republic (CAC), can be identified different characters that lead to the confirmation or refutation of the conclusion on trademark infringement on a specific website on particular domain name. For selected characters, it is necessary to define clear semantics and rules so a computer algorithm will be able to decide whether a specific domain name or a website is in compliance with them or not. Then, within the set of monitored domain names and trademarks, it will be possible to statistically determine which characters are typical for both types of domain names, those that do abuse trademarks and those that do not.

First of all it is necessary to define the input sources. As mentioned, the attention will be focused on the area of the Czech domain, therefore, it is necessary to get a current list of domain names in the .cz domain, which is about to be analyzed. As a source of trademarks will be used the database of the Industrial Property Office (IPO). Given the need of finding out which domain names are relevant to the particular trademark, it opens the possibility of detecting the extent in which the words contained in the trademark appear in the text of the domain name. This way it is possible to link one with the other. The mere determination of whether a trademark is part of the text of a domain name is not entirely accurate. For example, the trademark "audi" is part of the text of the domain "audio.cz" although there is no relationship between the two. In the article, therefore, will be used a more precise mechanism using Czech dictionary and Thesaurus of Czech words. The textual representation of domain names and trademarks will be separated using a thesaurus on individual words and the coincidence between trademarks and domain names will be further examined at the level of words. The above example of audi vs. audio. $c z$ will have already traversed correctly. Upon found relationships between domain names and trademarks will be performed fundamental analysis, which will provide answers to questions such as, how many percent of domain names in the .cz domain is related to a trademark, how many domain names on average are related to one trademark or which trademarks are the most represented on the Czech Internet. It is possible to search the words constituting the trademark not only in the text of the domain name but also in the text of a website. Such comprehensive research, however, is outside the scope of this article. We will work with the assumption that the trademark is represented in some way in the text of the domain name, as this practice is more or less taken into account by Internet search engines (Janouch, 2014); Internet users, while searching for pages that relate to the particular trademark, may type the text of the trademark directly as a domain name 
(example: cocacola.cz, coca-cola.cz, skodaauto.cz, etc.).

The sector of the automotive industry will be studied further in detail. In order to ascertain the effect of the occurrence of particular characters on the determination whether a trademark is infringed on a website or not, the method of logistic regression (Kleinbaum et al., 2010) will be used. In order to perform analysis, it is necessary to go manually through the monitored domain names (approximately 1600 domain names) while taking into account the decision-making practice (WIPO and CAC) and accordingly divide them into two categories: those in the conflict of law (trademark infringing) and non-conflictive (no infringement) hereinafter referred to as collision/non-collision. Using defined explanatory characters, the category of collision/non-collision is going to be explained via regression analysis.

\section{Data Acquisition and its Processing}

\subsection{List of Domain Names}

For the acquisition of the current list of domain names .cz is the best to get the information directly from the database administrator of the domain CZ.NIC, Interest Association of Legal Entities. The administrator, however, refuses to provide the data, albeit only for research purposes. For this reason, a list of domain names, current to January 2015 and provided by CESNET, Interest Association of Legal Entities serves as a base data file. Although, the disadvantage of the list is its incompleteness.
There are 517,655 domain names out of $1,178,891$, which makes approx. $44 \%$ of the total number of registered domain names at CZ.NIC in that time. To refine the list of current domain names there were used additional sources of domain names listed on czdomeny. $C z$ and domainpunch.com. This resulted in an overall list containing 568,272 Czech domain names, which are used further on.

\subsection{List of Trademarks}

In another part of the article, there is for the selected trademarks detected a link between relevant domain names and content of websites connected to these domain names, which will then be used for the analysis of socalled Characters. On the territory of the Czech Republic, trademarks listed in Section 2 of Act No. 441/2003 Coll. on trademarks, shall enjoy the protection of trademark. The current list of national trademarks is publicly available on the IPO website. From the database of IPO were downloaded 474,222 unique lexical trademarks by using a computer program. Trademarks are made up of phrases where each word is separated by a space (e.g. audi spare parts or genuine škoda accessories). Registered trademarks consist of 1.72 words in average. The following Tab. 1 shows the layout of a number of trademarks for a specific number of words.

Because of the computing requirements (search for links between approximately 470 thousand trademarks in relation to 560 thousand domain names) for the purpose of this article,

Tab. 1: The number of trademarks for a given word count

\begin{tabular}{c|c|c|c} 
Word count & Number of trademarks & \% & Sum \% \\
\hline 1 & 266,697 & $56.24 \%$ & $56.24 \%$ \\
\hline 2 & 133,919 & $28.24 \%$ & $84.48 \%$ \\
\hline 3 & 44,982 & $9.49 \%$ & $93.96 \%$ \\
\hline 4 & 16,378 & $3.45 \%$ & $97.42 \%$ \\
\hline 5 & 6,438 & $1.36 \%$ & $98.78 \%$ \\
\hline 6 & 3,032 & $0.64 \%$ & $99.41 \%$ \\
\hline 7 & 1,295 & $0.27 \%$ & $99.69 \%$ \\
\hline $8-1,000$ & 1,481 & $0.31 \%$ & $100.00 \%$ \\
\hline Total & 474,222 & $100.00 \%$ & \\
\hline
\end{tabular}




\section{Tab. 2: Words obtained from dictionaries and trademarks}

\begin{tabular}{l|c|c}
\multicolumn{1}{c|}{ The source } & Word count & $\%$ \\
\hline The word obtained exclusively from the trademarks & 286,541 & $49.83 \%$ \\
\hline $\begin{array}{l}\text { The words obtained from dictionaries and lists of } \\
\text { municipalities and names }\end{array}$ & 253,311 & $44.05 \%$ \\
\hline The words contained in both sources & 35,179 & $6.12 \%$ \\
\hline Total & 575,031 & $100.00 \%$ \\
\hline
\end{tabular}

Source: own

there are only used such trademarks that consist of 5 and less words - these make up $97.42 \%$ of all trademarks. For the same reasons this work focuses only on those trademarks having $4-160$ characters (these make up over $98 \%$ of all trademarks). Trademarks may contain words of Czech language, names of people, etc. For such trademarks and particularly domain names that are paired to them, it is difficult to determine whether the domain name refers to the meaning of the word commonly used in the Czech language or to trademark rights (e.g. trademark registered in IPO "Osamělý vlk"). In this article, therefore, we will focus only on trademarks which have more distinctive eligibility and do not contain only Czech words of generic or descriptive character (especially because of the power of efficiency of trademark on the Internet). From a total of 474,222 trademarks, 361,007 of them meet these criteria $(76.13 \%)$.

\subsection{Other Resources}

In order to determine whether a trademark contains Czech words, it is necessary to use the current Czech Dictionary or the Czech Corpus. For these purposes, it is used the Czech language corpus of SYN2010 from the Institute of the Czech National Corpus. When analyzing the relationship of domain names and trademarks it is necessary to split the domain name into individual words, in order to determine compliance with the trademark (e.g., for "mojeaudi.cz" the domain name needs to be split into words "moje" and "audi" to determine the continuity of the audi's trademark). Domain names, however, not only consist of Czech words but also of English words. They commonly contain the names of municipalities or first and last names of people (e.g., myaudi.cz - a composition of the English word "my" and the trademark of "audi"; bartekskoda.cz - a composition of last name "Bártek" and the trademark of "skoda"; audipraha.cz - a composition of the trademark "audi" and city name "Prague", etc.). The total work corpus that is used to split domain names to single words, contains the Czech language corpus of SYN2010 (Institute of the Czech National Corpus), the English language corpus (GNU-FDL English-Czech Dictionary), list of Czech municipalities, list of Czech names and surnames, words found in trademarks of IPO database. Because of the computing requirements, words of less than 4 characters are taken off, unless those are prepositions or conjunctions of Czech or English language. The total resulting corpus contains 575,031 words, of which about half comes from neologisms extracted from trademarks.

\section{Analysis of Correlations between Domain Names and Trademarks}

With the available resources can be done a general analysis of correlations between trademarks and domain names. It is necessary to answer the question of which domains are relevant for a given trademark. As an example the domain "servisrenault-stredoceskykraj. $c z$ " is relevant to the Renault trademark; the domain "vrakoviste-fiat-renault.cz" is relevant to both Renault and Fiat trademarks; however, domain "audiostezka.cz" is only relevant to the trademark "Audiostezka" but not to "Audi" trademark. As you can see in the examples, the correlation between trademarks and domain names is generally $\mathrm{N}: \mathrm{N}$, hence one trademark may be relevant in multiple domain names, and a single domain can be relevant to more trademarks (e.g., the above referred "vrakoviste-fiat-renault.cz"). First, there will be used a simple way of finding a domain name 
for a trademark by a direct search for parts of the trademark in the text of the domain name. The algorithm first splits the trademark into individual parts according to a space (and other separators such as comma, semicolon, etc.) and then it searches whether the trademark is part of the text of a domain name. For example, a trademark "Potrefená husa" is first split into parts "potrefena" and "husa". Then the algorithm goes through all of the domain names and looks for such text, which contain both of the words. Relevant domains such as "potrefenahusa-design.cz", "potrefenahusazlin. cz" will so end up in the final result. However, this algorithm does not always work correctly. For example, the algorithm correctly finds domain names containing the trademark "audi", such as audi.cz or chiptuning-audi.cz, but it also finds domain names that have nothing in common with Audi trademark, such as aaudio. $c z$ or absoluteaudio.cz and others. Another, more complicated algorithm can tackle this problem using the Czech and English corpus to prevent such misleading match. The following Tab. 3 shows the result of the above-described algorithm process.

\section{Tab. 3: Parts of trademarks in the text of domain names}

\begin{tabular}{l|c|c} 
& Number of TM & $\%$ \\
\hline The TM is included in the text of a domain name & 61,482 & $17.03 \%$ \\
\hline The TM is NOT included in the text of a domain name & 299,525 & $82.97 \%$ \\
\hline Total & $\mathbf{3 6 1 , 0 0 7}$ & $\mathbf{1 0 0 . 0 0 \%}$ \\
\hline
\end{tabular}

Source: own

From the above, it is evident that for 61,482 $(17.03 \%)$ trademarks, there exists a domain name that consists of words contained in the trademark. Because we focused only on trademarks with more distinctive eligibility, which could potentially lead to a confusion of their meaning, we can assume that the domain names that were found can actually be relevant to those trademarks. As mentioned above, the simple text match algorithm has its weak spots and is shown here only for comparison. In the following text, there will be used a more complex algorithm, which is more accurate in the process of determining domain names for given trademark. The algorithm will use the Czech and English corpus, which shall split the trademarks and domain names into words and the match will be determined at the level of words. For the above mentioned "absoluteaudio.cz" the algorithm divides the domain name into English words "absolute" and "audio", making them no longer bound to the trademark Audi. The basic definition of the used algorithm:

1. For each domain name is searched a sequence of words based on the corpus, which a domain name consists of (for example, the words "moje" and "audi" put together create a domain name "mojeaudi.cz").
There is a function within the algorithm, which finds phrases that form a given domain name. The algorithm maximizes the function to find the best combination of words.

2. Trademarks are split into words. Characters such as space, comma, dot, etc. are used as separators.

3. By splitting domain names into words there are found relevant domain names for all 361,007 trademarks. It is essential that words contained in a trademark must also be part of the above-described domain name division into words.

The results of the above algorithm are shown in Tab. 4.

By using a more accurate algorithm was found that $43,436(12.03 \%)$ trademarks are linked to one or more of the Czech domain names. With knowledge of the links between trademarks and domain names, it is possible to specify how many Czech domain names were made with the intention to benefit from the existence of some of the trademarks. Of a total of 568,272 Czech domain names, 123,050 $(21.65 \%)$ domains are bound to a trademark, see the following Tab. 5 .

For one trademark that is bound to at least one domain name, there is an average of 3.04 


\begin{tabular}{l|c|c}
\multicolumn{1}{c|}{ The existence of a domain name in TM } & Number of occurrences & $\%$ \\
\hline The existence of a domain name for a TM & 43,436 & $12.03 \%$ \\
\hline There is no domain name for the TM & 317,571 & $87.97 \%$ \\
\hline Total & $\mathbf{3 6 1 , 0 0 7}$ & $\mathbf{1 0 0 . 0 0 \%}$ \\
\hline
\end{tabular}

Source: own

\section{Tab. 5: Czech domain names and their binding to the trademarks}

\begin{tabular}{l|c|c}
\multicolumn{1}{c|}{ Domain name } & Number of occurrences & $\%$ \\
\hline Domain name is bound to a TM & 123,050 & $21.65 \%$ \\
\hline Domain name is not bound to a TM & 445,222 & $78.35 \%$ \\
\hline Total & $\mathbf{5 6 8 , 2 7 2}$ & $\mathbf{1 0 0 . 0 0 \%}$ \\
\hline
\end{tabular}

Source: own

domain names. One single registered domain name has 24,620 trademarks (56.68 \%), two domain names have 6,716 trademarks (15.46\%). $79.55 \%$ trademarks have the average number of 3 domain names per trademark. Although the average number of domain names to a single trademark is approx. 3 domain names, there are trademarks that have hundreds of them. As an example there are 239 domain names with a "Škoda" trademark, 110 with "Apple", 75 with "Bosh". For our analysis, it is important there are in average 63 domain names per trademark within the automotive industry, so it is possible to examine the usage of a trademark on such domains in more detail. It is also possible to ask a question whether an actual transcription of the trademark to a domain name follows some simple rules. For example, how often does a single-word trademark directly transcript to a domain name, e.g., "Škoda" to "skoda.cz", or multi-word "Potrefená husa" to "potrefenahusa. $c z$ " or "potrefena-husa.cz". The frequency of these transcriptions is shown in Tab. 6. The biggest volume of direct transcription of a trademark into a domain name, such as "A" into "A.CZ" amounts to $51.81 \%$ as expected. Multi-word transcriptions or those with an added character "-" are a rather minor issue (4.44\%). The remaining $43.76 \%$ are other, more complex transcripts. Particularly those with an addition of

\section{Tab. 6: The frequency of some transcriptions of trademarks to a domain name}

\begin{tabular}{l|c|c}
\multicolumn{1}{c|}{ Transcript (TM -> domain name) } & Number of cases & $\%$ \\
\hline A -> A.cz & 31,851 & $51.81 \%$ \\
\hline A B -> AB.cz & 2,159 & $3.51 \%$ \\
\hline A B C -> ABC.cz & 152 & $0.25 \%$ \\
\hline A B C D -> ABCD.cz & 19 & $0.03 \%$ \\
\hline A B -> A-B.cz & 383 & $0.62 \%$ \\
\hline A B C -> A-B-C.cz & 13 & $0.02 \%$ \\
\hline A B C D -> A-B-C-D.cz & 2 & $0.00 \%$ \\
\hline Another transcript (use of generic or descriptive words) & 26,903 & $43.76 \%$ \\
\hline Total & $\mathbf{6 1 , 4 8 2}$ & $\mathbf{1 0 0 . 0 0 \%}$ \\
\hline
\end{tabular}


Tab. 7: The most common transcriptions of a trademark into a domain name (top 20)

\begin{tabular}{|c|c|c|}
\hline Order & Pattern for TM & Number of domains \\
\hline 1 & $\{T M\}$ shop.cz & 649 \\
\hline 2 & $\mathrm{e}\{\mathrm{TM}\} . \mathrm{cz}$ & 538 \\
\hline 3 & $\mathrm{i}\{\mathrm{TM}\} . \mathrm{cz}$ & 443 \\
\hline 4 & $\{$ TM\}-shop.cz & 334 \\
\hline 5 & $\{$ TM\}club.cz & 254 \\
\hline 6 & $\{$ TM\}service.cz & 245 \\
\hline 7 & auto $\{\mathrm{TM}\} . \mathrm{CZ}$ & 224 \\
\hline 8 & $\{$ TM\}group.cz & 223 \\
\hline 9 & studio $\{\mathrm{TM}\} . \mathrm{cz}$ & 220 \\
\hline 10 & hotel $\{T M\} . c z$ & 217 \\
\hline 11 & $\{$ TM\}web.cz & 211 \\
\hline 12 & $e-\{T M\} . c z$ & 203 \\
\hline 13 & $\{\mathrm{TM}\}$ design.cz & 200 \\
\hline 14 & $\{$ TM\}praha.cz & 199 \\
\hline 15 & for $\{T M\} . c z$ & 193 \\
\hline 16 & $\{$ TM\}-praha.cz & 181 \\
\hline 17 & $\{$ TM\}brno.cz & 170 \\
\hline 18 & $\{$ TM\}plus.cz & 156 \\
\hline 19 & $\{$ TM\}reality.cz & 153 \\
\hline 20 & salon $\{\mathrm{TM}\} . \mathrm{cz}$ & 151 \\
\hline
\end{tabular}

another generic or descriptive expression, such as a transcript of a trademark " $A$ " to "prahaA.cz" or to "e-A.cz", etc.

The words, both generic and descriptive that are mostly used to form a domain name on the Czech Internet are "shop" (4,135 domains), "praha" (3,974 domains), "pro" (3,761 domains), "auto" (3,691 domains), "servis" (3,401 domains) and "brno" (3,220 domains). If, when using a division of a domain name into words, it is discovered that a trademark is incorporated into a domain name it is possible to examine patterns according to which a domain name is formed (beyond the simple transcription already referred to as "A" to "A.cz"). The most common patterns, where TM stands for a trademark, include TMshop.cz (649 domain names), eTM.cz (538 domain names), iTM.cz (443 domain names), TM-shop.cz (334 domain names), TMclub.cz (254 domain names), TMservis.cz (245 domain names), autoTM.cz (224 domain names), etc. The top 20 transcriptions are shown in Tab. 7.

\subsection{Definition of Monitored Characters}

In this section will be defined testable characters that will be detected for each trademark and its domain names using a computer program. The characters themselves originate in existing decisions of the WIPO and CAC directly. Some characters were derived indirectly so their influence on trademark infringement is to be further verified. Characters will be further analyzed through regression analysis and we will ask a question of how the existence of found characters relates to authorized/unauthorized use of a trademark on a given domain/website.

For the purpose of this article, 17 characters were defined to be further examined among domain names/websites associated with trademarks within the automotive industry. In the following text, we will use an expression "website has a given character" if the conditions defining the character are met (e.g., the website contains HTML frames element). As shown further, some of the characters are either not 
much used in practice (small representation across domain names examinees) or they are used extensively, but do not have a relevant value in order to determine whether the occurrence of the character rather leads to trademark infringement or not. The characters have been defined on the basis of an earlier analysis on indicators of domain names in conflict-of-law (Gongol, 2013). Here are the characters in question:

00 - No Page - Website has no content;

01 - Park - Website is "parked";

02 - Forward - Website is automatically redirected to another website;

03 - Size - Website content is very small; 04 - GLinks - Website contains a link to an official website of a trademark owner;

05 - Title - Website name contains a text of a trademark;
06 - GKeywords - Website's metadata contain a text of a trademark;

07 - SKeywords - Website's metadata contain suspicious words;

08 - Ads - Website contains advertising;

09 - SURL - Website's URL is suspicious;

10 - Frames - Website contains HTML frames;

11 - SContent - Website of suspicious content;

12-GOwner - Domain name belongs to a trusted holder;

13 - BForward - Website has an automatic redirection to the competition;

14 - BOwner - Website is located on a domain belonging to a suspicious holder;

15-BLinks - Website contains a link to a website in conflict-of-law;

16-NoTM - Website does not contain a reference to a trademark.

Tab. 8: Trademarks with the largest percentage of domains categorized as in collision

\begin{tabular}{l|c|c|c}
\multicolumn{1}{c|}{ Trademark } & In collision & $\%$ & Number of domains \\
\hline kia & 21 & $55.26 \%$ & 38 \\
\hline mercedes & 30 & $54.55 \%$ & 55 \\
\hline renault & 46 & $52.27 \%$ & 88 \\
\hline toyota & 30 & $49.18 \%$ & 61 \\
\hline peugeot & 26 & $49.06 \%$ & 53 \\
\hline mazda & 17 & $45.95 \%$ & 37 \\
\hline fiat & 33 & $43.42 \%$ & 76 \\
\hline ford & 56 & $42.75 \%$ & 131 \\
\hline audi & 17 & $42.50 \%$ & 40 \\
\hline skoda & 96 & $41.03 \%$ & 234 \\
\hline hyundai & 29 & $40.28 \%$ & 110 \\
\hline bmw & 44 & $40.00 \%$ & 32 \\
\hline jeep & 12 & $37.50 \%$ & 25 \\
\hline mitsubishi & 9 & $36.00 \%$ & 45 \\
\hline suzuki & 16 & $35.56 \%$ & 65 \\
\hline opel & 23 & $35.38 \%$ & 41 \\
\hline porsche & 14 & $34.15 \%$ & 66 \\
\hline honda & 21 & $31.82 \%$ & 38 \\
\hline nissan & 12 & $31.58 \%$ & 42 \\
\hline subaru & 13 & $30.95 \%$ & 83 \\
\hline citroen & 25 & $30.12 \%$ & \\
\hline & & & \\
\hline
\end{tabular}




\subsection{Manual Categorization of Domain Names that are Relevant to the Sector of the Car Industry}

Bearing in mind the objective of the article, detailed analysis is focused on the sector of the automotive industry particularly because in this sector exists in average a large number of relevant domain names to trademarks (63 domain names to a single trademark). Other reasons are the anticipated volume of investments in this sector and also a general awareness and demand from ordinary Internet users. Noteworthy is also the fact that the trademark in the automotive sector has a strong distinctive character, which reduces the risk of interchangeability.

All trademarks for which there was at least one relevant Czech domain name were selected for the analysis. If, in addition to the car manufacturer's trademark there were domain names for a particular type of product linked with the trademark (such as "Fabia"), these domain names were also included in the selection. Using an algorithm of the exact match at the level of words there were found 1,825 Czech domain names to such trademarks.

The intention of manual categorization process is to go through these domain names and determine, whether they are in conflict-oflaw/in collision - if so, it is a case of trademark infringement or they are in no conflict-oflaw/non-collision - in which case there is no unauthorized use of a trademark (a website is the official website of the owner of the trademark or it has been used legitimately by a third party). Of a total number of 1,621 existing domain names, there were $664(40.96 \%)$ categorized as collision, the remaining 957 (59.04\%) as a noncollision. For example, the trademark Škoda has 96 domain names in collision out of 234 relevant ones $(41.03 \%)$, the $B M W$ trademark has 44 in collision out of 110 (40.00\%). Among trademarks which have the largest number of domain names categorized as in collision are Kia $(55.26 \%)$, Mercedes $(54.55 \%)$, Renault (52.27\%), for more see Tab. 8.

First, while examining domain names in detail, it is important to find repetitive patterns that were used when forming a domain name out of a trademark. Once it is done it is possible to determine how many times the patterns were used for domain names that are categorized as in collision and non-collision. For example, the pattern TMweb.cz, from which may arise domain names such as skodaweb.cz, fordweb. $c z$, renaultweb.cz, etc. were used in 28 cases, all of which have been categorized as domains in collision. Similarly, the chiptuning-TM.cz pattern was used in 16 cases and in all of them the domain was categorized as in collision. For a detailed overview of the top twenty of the most frequent patterns, see Tab. 9.

\subsection{Regression Analysis of the Relationship between Characters and the Category of a Eomains Name}

In this part, we will focus on connections between the occurrence of specific characters and assigning of a domain name into collision or non-collision category. The aim is to identify a set of characters for which the automatic tracking makes the most sense and which determine the domain's probable category with an acceptable level of error. Then it would be possible to extend the results outside the area of the automotive industry in the follow-up research and use them for the next automatic analysis of domain names on the Internet. However, as mentioned above, it will not be possible to generalize the statistical findings to all domain names, as the result would be negatively influenced by a selective error. For all Czech domain names that were closely examined by the computer program were found their specific characters (total of 1,621 domain names). The three most commonly represented characters are 05 - Title $(66,66 \%$ of domain names), 06 - GKeywords $(47,13 \%$ of domain names), and 11 - SContent (25,35\% of domain names). On the other hand, the characters 13 - BForward and 10 - Frames do not appear in examined domain names almost at all (occurrence under 1\%). Therefore, given their insignificance, they will not be included in further analysis. The scale of the occurrence of individual characters is shown in Tab. 10 in detail.

Before a logistic regression model is applied, we will examine the relationship between the occurrence/absence of a specific character and a resulting category of a domain name applying the method of conditional probability.

$$
\mathrm{P}(A \mid B)=\frac{P(A \cap B)}{P(B)}
$$




\begin{tabular}{|c|c|c|c|c|c|}
\hline Pattern in domain & $\begin{array}{c}\text { Number } \\
\text { of domains }\end{array}$ & In collision & $\begin{array}{c}\text { In } \\
\text { collision } \% \\
\end{array}$ & Non-collision & Non-collision \% \\
\hline$\{$ TM\}web.cz & 28 & 28 & $100.00 \%$ & 0 & $0.00 \%$ \\
\hline$\{$ TM $\}$ club.cz & 27 & 18 & $66.67 \%$ & 9 & $33.33 \%$ \\
\hline$\{$ TM\}-auto.cz & 20 & 4 & $20.00 \%$ & 16 & $80.00 \%$ \\
\hline chiptuning-\{TM\}.cz & 16 & 16 & $100.00 \%$ & 0 & $0.00 \%$ \\
\hline$\{$ TM\}-klub.cz & 15 & 12 & $80.00 \%$ & 3 & $20.00 \%$ \\
\hline$\{\mathrm{TM}\}$-forum.cz & 15 & 15 & $100.00 \%$ & 0 & $0.00 \%$ \\
\hline$\{\mathrm{TM}\}$-club.cz & 13 & 5 & $38.46 \%$ & 8 & $61.54 \%$ \\
\hline$\{$ TM\}-praha.cz & 12 & 7 & $58.33 \%$ & 5 & $41.67 \%$ \\
\hline$\{$ TM\}levne.cz & 12 & 12 & $100.00 \%$ & 0 & $0.00 \%$ \\
\hline$\{$ TM\}praha.cz & 11 & 4 & $36.36 \%$ & 7 & $63.64 \%$ \\
\hline portal-\{TM\}.cz & 11 & 11 & $100.00 \%$ & 0 & $0.00 \%$ \\
\hline$\{\mathrm{TM}\}$ centrum.cz & 11 & 7 & $63.64 \%$ & 4 & $36.36 \%$ \\
\hline$\{$ TM\}brno.cz & 10 & 3 & $30.00 \%$ & 7 & $70.00 \%$ \\
\hline$\{$ TM\}dily.cz & 10 & 6 & $60.00 \%$ & 4 & $40.00 \%$ \\
\hline$\{$ TM\}klub.cz & 10 & 6 & $60.00 \%$ & 4 & $40.00 \%$ \\
\hline$\{$ TM\}-servis.cz & 9 & 5 & $55.56 \%$ & 4 & $44.44 \%$ \\
\hline$\{$ TM\}-dily.cz & 9 & 2 & $22.22 \%$ & 7 & $77.78 \%$ \\
\hline nahradnidily $\{\mathrm{TM}\} . \mathrm{cz}$ & 8 & 8 & $100.00 \%$ & 0 & $0.00 \%$ \\
\hline autovrakoviste $\{\mathrm{TM}\} . \mathrm{cz}$ & 8 & 6 & $75.00 \%$ & 2 & $25.00 \%$ \\
\hline$\{$ TM\}vrakoviste.cz & 8 & 5 & $62.50 \%$ & 3 & $37.50 \%$ \\
\hline
\end{tabular}

The statement $P(A \mid B)$ expresses the conditional probability of the phenomenon A provided that there occurred phenomenon B (e.g, the probability of the collision provided there occurred the character "with 08"). For example, to determine the probability of categorizing a domain name as in collision $(P(A \mid B))$ provided the occurrence of character $B$ it is necessary to know the probability of its occurrence in domain names in collision $(P(A \cap B))$ and divide it by the overall probability of the occurrence of character $\mathrm{B}$ across all examined domains $(P(B))$. Tab. 11 contains a list of probabilities for all examined characters that we can use to calculate all conditional probabilities.

Further on (in Tab. 12) there are calculated conditional probabilities in all combinations of occurrence/absence of characters. These lead to a determination of category in collision (it is then possible to calculate the probability of noncollision by counting the remainder to $100 \%$ ). Lines in red relate to characters for which there is a low percentage of occurrence (under $1 \%$ ) and which, despite high probabilities, will not be considered given their inconclusiveness (e.g, 13 - BForward 100\%). From Tab. 12, it is also evident that the absence of a particular character (column Without Character) does not have a significant impact on the determination of category since the data is around $50 \%$ (thus in the range of coincidence, given there are only two possible options - collision/non-collision).

In the case of characters $00-N o P a g e$, 01 - Park, 08 - Ads, 09 - SURL, 11 - SContent, $14-$ BOwner and $16-$ NoTM it is obvious they are more likely to lead to the collision category. The characters 04-GLinks and 12-GOwner to the category of non-collision. For the following logistic regression (besides characters 00 to 16), 


\begin{tabular}{|c|c|c|c|c|}
\hline $\begin{array}{l}\text { Tab. 10: } \\
\text { Detailed } \\
\text { of the au }\end{array}$ & $\begin{array}{l}\text { f occurrenc } \\
\text { e industry }\end{array}$ & vidual & rs acros & names \\
\hline $\begin{array}{l}\text { Identification } \\
\text { of characters }\end{array}$ & $\begin{array}{c}\text { With } \\
\text { character }\end{array}$ & $\%$ & $\begin{array}{c}\text { Without } \\
\text { character }\end{array}$ & $\%$ \\
\hline 05 - Title & 1,080 & $66.63 \%$ & 541 & $33.37 \%$ \\
\hline 06 - GKeywords & 764 & $47.13 \%$ & 857 & $52.87 \%$ \\
\hline 11 - SContent & 411 & $25.35 \%$ & 1,210 & $74.65 \%$ \\
\hline 02 - Forward & 329 & $20.30 \%$ & 1,292 & $79.70 \%$ \\
\hline $04-$ GLinks & 306 & $18.88 \%$ & 1,315 & $81.12 \%$ \\
\hline 03 - Size & 303 & $18.69 \%$ & 1,318 & $81.31 \%$ \\
\hline 14 - BOwner & 289 & $17.83 \%$ & 1,332 & $82.17 \%$ \\
\hline 12 - GOwner & 285 & $17.58 \%$ & 1,336 & $82.42 \%$ \\
\hline $15-$ BLinks & 237 & $14.62 \%$ & 1,384 & $85.38 \%$ \\
\hline 08 - Ads & 203 & $12.52 \%$ & 1,418 & $87.48 \%$ \\
\hline $16-\mathrm{NoOz}$ & 132 & $8.14 \%$ & 1,489 & $91.86 \%$ \\
\hline 01 - Park & 111 & $6.85 \%$ & 1,510 & $93.15 \%$ \\
\hline $09-$ SURL & 51 & $3.15 \%$ & 1,570 & $96.85 \%$ \\
\hline 00 - NoPage & 39 & $2.41 \%$ & 1,582 & $97.59 \%$ \\
\hline 07 - SKeywords & 22 & $1.36 \%$ & 1,599 & $98.64 \%$ \\
\hline 13 - BForward & 9 & $0.56 \%$ & 1,612 & $99.44 \%$ \\
\hline 10 - Frames & 7 & $0.43 \%$ & 1,614 & $99.57 \%$ \\
\hline
\end{tabular}

Source: own

Tab. 11: Table of probabilities of occurrences of tracked characters

\begin{tabular}{l|c|c|c|c}
$\begin{array}{c}\text { Identification } \\
\text { of the character }\end{array}$ & $\begin{array}{c}\text { With character } \\
\text { \& in collision }\end{array}$ & $\begin{array}{c}\text { With character } \\
\text { \& non-collision }\end{array}$ & $\begin{array}{c}\text { Without character } \\
\text { \& in collision }\end{array}$ & $\begin{array}{c}\text { Without character } \\
\text { \& non-collision }\end{array}$ \\
\hline $00-$ NoPage & 34 & 5 & 630 & 952 \\
\hline $01-$ Park & 106 & 5 & 558 & 952 \\
\hline $02-$ Forward & 98 & 231 & 566 & 726 \\
\hline $03-$ Size & 153 & 150 & 511 & 807 \\
\hline $04-$ GLinks & 18 & 288 & 646 & 669 \\
\hline $05-$ Title & 368 & 712 & 296 & 245 \\
\hline $06-$ GKeywords & 286 & 478 & 378 & 479 \\
\hline $07-$ SKeywords & 20 & 2 & 644 & 955 \\
\hline $08-$ Ads & 200 & 3 & 464 & 954 \\
\hline $09-$ SURL & 42 & 9 & 622 & 948 \\
\hline $10-$ Frames & 1 & 6 & 663 & 951 \\
\hline $11-$ SContent & 355 & 56 & 309 & 901 \\
\hline $12-$ GOwner & 18 & 267 & 646 & 690 \\
\hline $13-$ BForward & 9 & 0 & 655 & 957 \\
\hline $14-$ BOwner & 262 & 27 & 402 & 930 \\
\hline $15-$ BLinks & 177 & 60 & 487 & 897 \\
\hline $16-$ NoOz & 108 & 24 & 556 & 933 \\
\hline
\end{tabular}


The conditional probability of occurrence/absence of characters and their effect on the probability of determining the collision/non-collision category

\begin{tabular}{l|c|c}
\multicolumn{1}{c|}{ Character - factor } & With character \& in collision & Without character \& in collision \\
\hline $00-$ NoPage & $87.18 \%$ & $39.82 \%$ \\
\hline $01-$ Park & $95.50 \%$ & $36.95 \%$ \\
\hline $02-$ Forward & $29.79 \%$ & $43.81 \%$ \\
\hline $03-$ Size & $50.50 \%$ & $38.77 \%$ \\
\hline $04-$ GLinks & $5.88 \%$ & $49.13 \%$ \\
\hline $05-$ Title & $34.07 \%$ & $54.71 \%$ \\
\hline $06-$ GKeywords & $37.43 \%$ & $44.11 \%$ \\
\hline $07-$ SKeywords & $90.91 \%$ & $40.28 \%$ \\
\hline $08-$ Ads & $98.52 \%$ & $32.72 \%$ \\
\hline $09-$ SURL & $82.35 \%$ & $39.62 \%$ \\
\hline $10-$ Frames & $14.29 \%$ & $41.08 \%$ \\
\hline $11-$ SContent & $86.37 \%$ & $25.54 \%$ \\
\hline $12-$ GOwner & $6.32 \%$ & $48.35 \%$ \\
\hline $13-$ BForward & $100.00 \%$ & $40.63 \%$ \\
\hline $14-$ BOwner & $90.66 \%$ & $30.18 \%$ \\
\hline $15-$ BLinks & $74.68 \%$ & $35.19 \%$ \\
\hline $16-$ NoOz & $81.82 \%$ & $37.34 \%$ \\
\hline
\end{tabular}

Source: own

will be considered another categorical variable to determine whether a domain name is in collision or not (so-called Collision Factor). In order to find relationships between characters and the Collision Factor will be applied a logistic regression with the level of significance $\alpha=5 \%$. When examining the dependencies it is necessary to prevent a strong correlation links, which could negatively affect the resulting regression model. This way it is possible to find 16 statistically significant relationships out of 153 possible. As expected, the Collision Factor is strongly correlated $(>0.33)$ to characters $04-$ GLinks, 08 - Ads, 11 - SContent, 12 - GOwner, 14 - BOwner. Also, there are dependencies between the individual characters: strongly correlated $(>0.4)$ is a $16-$ NoTM with characters 01 - Park, 03 - Size, 05 - Title, then character 14 - BOwner with 08 - Ads, 11 - SContent and character 15 - BLinks with 11 - SContent and 14 - BOwner. We take these dependencies into account when reducing the found logistic model. The remaining dependencies have a coefficient below 0.3 so these rates of association can be considered insignificant.
It is now possible to create a logistic regression model (see, for example, Kleinbaum et al., 2010) in order to describe the association between both explanatory factors, "characters" and dependent "Collision Factor". As mentioned, for the lack of occurrence the characters 10 - Frames and 13 - BForward are excluded from the default model. For the sake of brevity, [00] [01] [02] in square brackets reflect the categorical parameters of independent characters 00 - NoPage, 01 - Park, 02 - Forward, etc.

$$
\begin{aligned}
& \operatorname{logit}(P(\text { collision }=1)) \\
& \quad=\beta_{0}+\beta_{1} \times[00]+\beta_{2} \times[01]+\beta_{3} \times[02]+ \\
& \quad+\beta_{4} \times[03]+\beta_{5} \times[04]+\beta_{6} \times[05]+ \\
& \quad+\beta_{7} \times[06]+\beta_{8} \times[07]+\beta_{9} \times[08]+ \\
& \quad+\beta_{10} \times[09]+\beta_{11} \times[11]+\beta_{12} \times[12]+ \\
& \quad+\beta_{13} \times[14]+\beta_{14} \times[15]+\beta_{15} \times[16]
\end{aligned}
$$

Model converged 14 iterations from the default zero model with a value of -2 Log $(L)=2,193.9304$ to the target value -2 Log $(L)=731.4205$. The values of all the coefficients found including the limits $(\alpha=0.05)$ for each factor are shown in Tab. 13. 


\begin{tabular}{c|l|c|c|c|c|c|c} 
Tab. 13: Default logistic model \\
Beta & \multicolumn{1}{|c|}{ Character } & Coefficient & Deviation & p & E.R. & $\begin{array}{c}\text { Min } \\
(95 \%)\end{array}$ & $\begin{array}{c}\text { Max } \\
(95 \%)\end{array}$ \\
\hline 1 & $00-$ NoPage & 4.1751 & 0.5424 & 0 & 65.0472 & 22.4668 & 188.3283 \\
\hline 2 & $01-$ Park & 4.6121 & 0.6556 & 0 & 100.691 & 27.856 & 363.9668 \\
\hline 3 & $02-$ Forward & 0.4003 & 0.2603 & 0.1242 & 1.4922 & 0.8958 & 2.4857 \\
\hline 4 & $03-$ Size & 1.1558 & 0.2607 & 0 & 3.1767 & 1.9058 & 5.295 \\
\hline 5 & $04-$ GLinks & -1.2359 & 0.3639 & 0.0007 & 0.2906 & 0.1424 & 0.5929 \\
\hline 6 & $05-$ Title & -0.7502 & 0.2493 & 0.0026 & 0.4723 & 0.2897 & 0.7697 \\
\hline 7 & $06-$ GKeywords & -0.0494 & 0.2283 & 0.8286 & 0.9518 & 0.6084 & 1.4889 \\
\hline 8 & $07-$ SKeywords & -1.432 & 1.0313 & 0.165 & 0.2388 & 0.0316 & 1.8029 \\
\hline 9 & $08-$ Ads & 5.6256 & 0.6318 & 0 & 277.4512 & 80.432 & 957.0709 \\
\hline 10 & $09-$ SURL & 0.4696 & 0.7433 & 0.5275 & 1.5994 & 0.3726 & 6.8648 \\
\hline 11 & $11-$ SContent & 4.0475 & 0.2539 & 0 & 57.2561 & 34.8088 & 94.1792 \\
\hline 12 & $12-$ GOwner & -2.0854 & 0.3728 & 0 & 0.1243 & 0.0598 & 0.258 \\
\hline 13 & $14-$ BOwner & 2.3017 & 0.3436 & 0 & 9.9915 & 5.0949 & 19.594 \\
\hline 14 & $15-$ BLinks & 0.68 & 0.3801 & 0.0736 & 1.9739 & 0.937 & 4.1579 \\
\hline 15 & $16-$ NoTM & 1.7874 & 0.3767 & 0 & 5.9736 & 2.855 & 12.4986 \\
\hline 0 & Intercept & -2.3188 & 0.2509 & 0 & & & \\
\hline & & & & & & & \\
\hline
\end{tabular}

\begin{tabular}{|c|c|c|c|c|c|c|c|}
\hline Beta & Character & Coefficient & $\begin{array}{c}\text { Std. } \\
\text { Deviation }\end{array}$ & $\mathbf{p}$ & E.R. & $\begin{array}{l}\text { Min } \\
(95 \%)\end{array}$ & $\begin{array}{c}\operatorname{Max} \\
(95 \%)\end{array}$ \\
\hline 1 & 00 - NoPage & 4.0727 & 0.5307 & 0 & 58.7168 & 20.7511 & 166.1438 \\
\hline 2 & 01 - Park & 4.1072 & 0.5209 & 0 & 60.7741 & 21.893 & 168.7069 \\
\hline 3 & 03 - Size & 1.1444 & 0.2558 & 0 & 3.1404 & 1.9021 & 5.185 \\
\hline 4 & 04 - GLinks & -1.1627 & 0.3603 & 0.0013 & 0.3126 & 0.1543 & 0.6335 \\
\hline 5 & 05 - Title & -0.7749 & 0.2395 & 0.0012 & 0.4608 & 0.2882 & 0.7367 \\
\hline 6 & 08 -Ads & 5.7617 & 0.6316 & 0 & 317.8989 & 92.1941 & 1096.1626 \\
\hline 7 & 11 - SContent & 4.1125 & 0.2491 & 0 & 61.1005 & 37.4966 & 99.5629 \\
\hline 8 & 12 - GOwner & -2.0815 & 0.3691 & 0 & 0.1247 & 0.0605 & 0.2572 \\
\hline 9 & 14 - BOwner & 2.3286 & 0.3298 & 0 & 10.2639 & 5.3771 & 19.592 \\
\hline 10 & 16 - NoTM & 1.8956 & 0.3676 & 0 & 6.6564 & 3.2387 & 13.6805 \\
\hline 0 & Intercept & -2.2164 & 0.2245 & 0 & & & \\
\hline
\end{tabular}


Tab. 15: The test of credibility (likelihood) of the zero, default and reduced model

\begin{tabular}{l|c|c|c|c|c}
\multicolumn{1}{c|}{ Logistic model } & \#df & $\mathbf{- 2}$ Log (L) & df & D (chi-quadrate) & P (>D) \\
\hline Reduced model & 11 & 739.1572 & & & \\
\hline Zero model & 1 & $2,193.9304$ & -10 & $1,454.7732$ & $<0.00001$ \\
\hline Default model & 16 & 731.4205 & & & \\
\hline Reduced model & 11 & 739.1572 & -5 & 7.7367 & 0.1713 \\
\hline
\end{tabular}

Source: own

The coefficients for the characters [02], [06] [07], [9] and [15] have p-values greater than set significance level. Therefore, they are excluded from the reduced model. The original model, which contained 15 factors, is being reduced to a model with 10 factors having an equation:

$$
\begin{aligned}
& \operatorname{logit}(P(\text { collision }=1)) \\
& \quad=\beta_{0}+\beta_{1} \times[00]+\beta_{2} \times[01]+\beta_{3} \times[03]+ \\
& \quad+\beta_{4} \times[04]+\beta_{5} \times[05]+\beta_{6} \times[08]+ \\
& \quad+\beta_{7} \times[11]+\beta_{8} \times[12]+\beta_{9} \times[14]+ \\
& \quad+\beta_{10} \times[16]
\end{aligned}
$$

Reduced model converged 14 iterations to the value $-2 \log (L)=739.1572$. The calculated coefficients, including the limits of the estimate of the relative risk (E.R.), are shown in the following Tab. 14.

We will compare the significance of the reduced model with the zero one and also the default model by using the test of credibility (likelihood). The reduced model is significantly different from the zero one $(p<0.00001)$ and it is not remarkably different from the default model $(p=0.1713)$, see Tab. 15 .

Now we will create separate logistic models, in which we will examine the influence of every single character on the Collision Factor. Comparison of the relative change in the coefficients of a standalone logistic models with coefficients of the relative model can help reveal hidden dependencies between the characters. Relative changes in the coefficients are shown in Tab. 16.

It is clear that for the character 03 - Size there is a multiple value change (from 0.4768 to 1.1144$)$, which is explainable by a strong association with 01 - Park (Cramer's coefficient is 0.352 ) and character 16 - NoTM (Cramer's coefficient is 0.487 ). From the reduced model

\begin{tabular}{|c|c|c|c|}
\hline Tab. 16: $\begin{array}{l}\text { Rela } \\
\text { mod }\end{array}$ & langes in the coeff & of standalone $\mathrm{m}$ & id the reduced \\
\hline Parameter & Standalone model & Reduced model & Relative change \\
\hline 00 - NoPage & 2.3298 & 4.0727 & -0.7481 \\
\hline 01 - Park & 3.5882 & 4.1072 & -0.1446 \\
\hline 03 - Size & 0.4768 & 1.1444 & -1.4002 \\
\hline $04-$ GLinks & -2.7376 & -1.1627 & 0.5753 \\
\hline $05-$ Title & -0.8491 & -0.7749 & 0.0874 \\
\hline 08 - Ads & 4.9205 & 5.7617 & -0.1710 \\
\hline 11 - SContent & 2.9169 & 4.1125 & -0.4099 \\
\hline 12 - GOwner & -2.6310 & -2.0815 & 0.2089 \\
\hline 14 - BOwner & 3.1112 & 2.3286 & 0.2515 \\
\hline 16 - NoTM & 2.0217 & 1.8956 & 0.0624 \\
\hline
\end{tabular}
we will create the final model from which we will exclude the character 03 - Size. Also the character 05 - Title is strongly associated with the other parameters of the model (with 
Tab. 17: Test of credibility of the reduced and final model

\begin{tabular}{l|c|c|c|c|c}
\multicolumn{1}{c|}{ Logistic model } & \#df & $\mathbf{- 2}$ Log (L) & df & D(chi-quadrate) & P (>D) \\
\hline Reduced model & 11 & 739.1572 & & & \\
\hline Final model & 9 & 769.0925 & -2 & 29.9353 & $<0.00001$ \\
\hline Final model & 9 & 769.0925 & & & \\
\hline Zero model & 1 & $2,193.9304$ & -8 & $1,424.8379$ & $<0.00001$ \\
\hline
\end{tabular}

Source: own

the character 01 - Park - Cramer's coefficient 0.331 ) and the character $16-$ NoTM - Cramer's coefficient 0.42 ), therefore we will not consider it in the final model. The final model converged $\mathrm{k}-2 \log (\mathrm{L})=769.0925$ after 14 iterations. When comparing the reduced and final model using the credibility test, the final model differs significantly from the reduced one, see Tab. 17 .

We can write the equation of the resulting model as follows:

$$
\begin{aligned}
& \ln \left(\frac{P(\text { collision }=1)}{1-P(\text { collision }=1)}\right) \\
& \quad=-2.3284+4.1848 \times[00]+4.4662 \times \\
& \quad \times[01]-1.4546 \times[04]+5.3405 \times \\
& \quad \times[08]+3.7252 \times[11]-2.0853 \times \\
& \quad \times[12]+2.1862 \times[14]+2.9273 \times[16]
\end{aligned}
$$

where [00] is 1 if the domain has the given character and value of 0 if the domain name does not have the given character (by analogy to [01] [04], ...). The list of found coefficients including p-value is shown in Tab. 18.
From this can be concluded that the existence of the character $08-A d s$ significantly increase the chance that a website is in collision (about 200 times, column E.R. = odds ratio of the collision/non-collision). Similarly, character $00-N o P a g e$ increases the chance of it being in collision approximately 65 times, character 01 - Park 87 times. On the other hand, the existence of character 12 - GOwner reduces the chance of it being in collision 8 times. Similarly, the character $04-$ GLinks reduces the chance of about 5 times. The resulting model equation can be used to estimate the probability of "being in collision" based on the information of found characters for a given domain. For example, suppose a website has two characters: 08 - Ads and 11 - SContent. After substituting, the equation will look like this:

$$
\begin{aligned}
& \ln \left(\frac{P(\text { collision }=1)}{1-P(\text { collision }=1)}\right) \\
& \quad=-2.3284+4.1848 \times 0+4.4662 \times \\
& \quad \times 0-1.4546 \times 0+5.3405 \times 1+ \\
& \quad+3.7252 \times 1-2.0853 \times 0+2.1862 \times \\
& \quad \times 0+2.9273 \times 0=6.737
\end{aligned}
$$

Tab. 18: The final logistic model
\begin{tabular}{c|l|c|c|c|r|r|r} 
Beta & Character & Coefficient & Deviation & p & \multicolumn{1}{c|}{ E.R. } & Min (95\%) & Max (95\%) \\
\hline 1 & $00-$ NoPage & 4.1848 & 0.5028 & 0 & 65.6785 & 24.5148 & 175.9616 \\
\hline 2 & $01-$ Park & 4.4662 & 0.5107 & 0 & 87.0272 & 31.9864 & 236.7799 \\
\hline 3 & $04-$ GLinks & -1.4546 & 0.3433 & 0 & 0.2335 & 0.1191 & 0.4576 \\
\hline 4 & $08-$ Ads & 5.3405 & 0.6233 & 0 & 208.6105 & 61.4928 & 707.6978 \\
\hline 5 & $11-$ SContent & 3.7252 & 0.2223 & 0 & 41.4796 & 26.8271 & 64.1349 \\
\hline 6 & $12-$ GOwner & -2.0853 & 0.3619 & 0 & 0.1243 & 0.0611 & 0.2526 \\
\hline 7 & $14-$ BOwner & 2.1862 & 0.3086 & 0 & 8.9017 & 4.8613 & 16.3002 \\
\hline 8 & $16-$ NoTM & 2.9273 & 0.3215 & 0 & 18.6778 & 9.9454 & 35.0775 \\
\hline 0 & Intercept & -2.3284 & 0.1469 & 0 & & & \\
\hline
\end{tabular}


After removing the logarithm and the expression of values $P$ (collision $=1$ ), we get:

$$
P(\text { collision }=1)=\frac{e^{6.7373}}{1+e^{6.733}}=0.9988=99,9 \%
$$

Therefore, if the page has the characters 08 and 11 , then there is $99.9 \%$ probability that according to the model the website is in collision.

\section{Discussion}

When determining the relevance of a domain name for a particular trademark, an algorithm was used that sought the best breakdown of the domain name into individual words with the help of Czech and English language dictionaries and other support lists by using a function in its maximum potential. In the light of current technologies, it seems best for this type of task to use a self-taught neural or convolutional neural network that would itself find the best divisions.

Another part was aimed at finding the relevant characters, which typically occur on trademark infringing websites. The analysis showed, which characters should be followed further and which are of lower significance. In practical terms, there is a difficulty in the algorithmic implementation of characters for which it is necessary to know the specifics of the trademark sector. In the case of the examined automotive industry, it is a network of group links between automobile manufacturers, types of cars and their links, words whose appearance on the website is suspicious from the perspective of the automotive industry (for example, the word "perfume", "accommodation", etc.). Generalization of the analysis across other sectors, or the "whole Internet" in domain .cz, would be intriguing and under certain conditions even possible. Some characters that showed high relevance in determining domain name being in collisions do not require a sectoral knowledge (for example, character 08 -Website contains advertising, character 00 - NoPage or character 01 - Park) - an extension of the analysis would be straightforward for this type of characters. For some characters, such as character 11 - Website of suspicious content, a sectoral knowledge is necessary. However, obtaining such knowledge could also be possible through a well-designed self-taught algorithm based on neural networks. The analysis was in many ways based on a connection between an existing lexical trademark and a textual binding to the respective domain names (word division). However, there could be other binding options - for example, a phonetic one, or an option that takes typing errors into account or ignores the Czech diacritics.

Holders of domain names who commit a trademark infringement always do so for the sole purpose of their own benefit. They need to have Internet users navigated to their websites when searching a specific trademark. In some cases, there are holders controlling domain names in collision only, e.g. JAKUBELIAS controls 32 registered domain names with $100 \%$ of them being in collision and so do the others, e.g. WEBDEVEL, PROFIWHPETRANOVAKOVA, MITONCZ. An Internet user who needs to find relevant websites of a trademark uses either a direct URL, which they deduce by an intuitive transcription of the trademark into a domain name and put it in the address bar of the browser or they use a search portal. The analysis showed the relevance of direct transcription of a trademark into a domain name in $51.81 \%$ of registered trademarks. A common SEO practice to embed keywords and relevant information into a domain name (in our case, a trademark) retreats with the advent of more advanced search algorithms. Therefore, it will be beneficial to link the user, trademark and relevant domain names via Internet search engines themselves, i.e. enter the trademark into the search engine using a program and identify top 10 results as relevant.

Detailed analysis dealt with the influence of characters on the dichotomy factor of collision/non-collision, mainly in order to find characters that typically lead to a domain name in collision and that could be used, for example, in a computer program for automatic search of websites in collision. For practical purposes, in any other analysis, it will be useful to divide the collision factor into multiple categories according to the severity or nature of the infringement (systematic trademark infringement, misuse of a trademark arising from lack of knowledge, etc.).

\section{Conclusions}

The text analyzed the links of 568 thousand Czech domain names in relation to 361 
thousand trademarks from IPO registry. For the 43 thousand trademarks $(12 \%)$ there exists at least one relevant Czech domain name and 123 thousand domain names (21.65\%) have a connection to a trademark. There is an average of 3 domain names per trademark that has at least one domain name. In the sector of the automotive industry that was examined in detail, there are even 63 domain names per trademark. Over $51 \%$ of trademarks use a direct transcription of the trademark name into the domain name by excluding gaps and removing diacritics. Other most common transcriptions of trademarks include (TM)shop. cz, e(TM).cz, i(TM).cz, (TM)-shop.cz, (TM)club. $c z$. In accordance with research questions, the analysis focused on the automotive sector, where there were examined 1621 domain names in detail, of which 664 (40.96\%) were categorized as in collision because of the found trademark infringement. The following trademarks show the highest percentage of website abuse: Kia (55.26\%), Mercedes $(54.55 \%)$, Renault $(52.27 \%)$ and Toyota $(49.18 \%)$. The lowest percentage applies to Citroen (30.12\%), Subaru (30.95\%), Nissan $(31.58 \%)$ and Honda (31.82\%). Patterns typical for trademark infringement within automotive industry include (TM)web.cz, (TM)levne. CZ, chiptuning-(TM).cz, portal-(TM).cz. The first research question, whether trademark infringement is a marginal issue or widespread practice, can be answered, at least in the case of the automotive industry, in favor of a widespread practice.

The second research question concerning the existence of similar or mutual characters of domain names/websites in violation of trademark rights, we need to answer in the affirmative. Based on the analysis of the domain disputes, there were examined 17 characters and their effect on increasing the collision risk of a domain name. The following characters are among the significant factors: 08 - Website contains advertising, 11 - Website of suspicious content, 16 - Website does not contain a reference to a trademark, 00 - Website has no content, 01 - Website is "parked", 14 - Website is located on a domain belonging to a suspicious holder. Conversely, the presence of the following characters significantly reduces the risk of a domain name being in collision: 04 - Website contains a link to an official website of a trademark owner and character
12 - Domain name belongs to a trusted holder. According to the analysis, some of the other characters statistically proved to be insignificant (e.g. 02 - Website is automatically redirected to another website).

The last research question tackled the possibility of an automated search for specific cases of unauthorized use of trademarks, resp. finding general rules for such a system. Partial analyses were focused on the automotive industry. A simple extension over the entire Internet, resp. all domain names would be burdened with a selection error. Nevertheless, generalizing the analysis across other sectors or the entire Internet within ".cz" domain is possible under certain conditions. Some characters that reported high relevance in determining domain name collisions do not require a sectoral knowledge (e.g., 08 - Website contains advertising, 00 - Website has no content, 01 - Website is "parked"/has unreleased content) - for these characters the extension of the analysis is straightforward. For some others, such as character 11 - Website of suspicious content, the sectoral knowledge is necessary (this can be obtained, for example by a well-designed self-taught algorithm based on neural networks).

The above also shows the possible direction for further research. In addition to the extension of the analysis across the entire ".cz" domain it is possible, within the framework of the methodology to keep adding new characters that indicate a domain name in collision/non-collision. For example, the links formed by the phonetic similarities or typos, date of registration of the trademark against domain name registration, prevention of access of indexing robots to Websites, etc. Finding a link between a trademark and a domain name based on Internet search engines would also be highly beneficial. Not only for the purpose of identifying the trademark's distinctive character, but also to find relevant domain names that appear in the references as natural search results.

The results of the carried out research show practical possibilities to limit the trademark infringement on the Internet by automated means that can be used by both, the entities protecting the rights of trademark proprietors and, where appropriate, administrators of national or generic domains, provided they accepted the possibility, albeit only of a partial, 
automated process of detecting a registered domain name collision with an existing trademark.

This paper was supported by the Student grant competition project SGS/7/2017: "Acceptance of technology from the perspective of marketing tools."

\section{References}

Bettinger, T., Willoughby, T., \& Abel, S. (2005). Domain name law and practice: an international handbook. New York, NY: Oxford University Press.

Burmann, C., Riley, N. M., Halaszovich, T., \& Schade, M. (2017). Identity-Based Brand Management. Wiesbaden: Springer Gabler.

Branthover, N. (2002). UDRP - A Success Story: A Rebuttal to the Analysis and Conclusions of Professor Milton Mueller in „Rough Justice“. International Trademark Association. Retrieved July 23, 2019, from https://www.inta.org/Advocacy/Documents/ INTAUDRPSuccesscontraMueller.pdf.

Crass, D., Czarnitzki, D., \& Toole, A. A. (2019). The Dynamic Relationship Between Investments in Brand Equity and Firm Profitability: Evidence Using Trademark Registrations. International Journal of the Economics of Business, 26(1), 157-176. https://doi.org/10.1080/13571516.2019.1553292.

Edwards, L., \& Waelde, Ch. (2009). Law and the internet. 3rd ed. Oxford: Hart publishing.

Gielen, Ch. (2010). Keyword advertising and European Trade Mark Law, Retrieved July 22, 2019, from http://charlesgielen.com/2.html.

Gongol, T. (2012). The Analysis of Czech Arbitral Court Verdicts in Cases. DANUBE/Law and Economics Review, 3(1), 71-93.

Gongol, T. (2013). Právní aspekty nekalé soutěže na internetu. Karviná: Silesian University in Opava, Faculty of Business Administration in Karviná.

Gongol, T. (2013b). The Preliminary Ruling Decision in the Case of Google vs. Louis Vuitton Concerning the AdWord Service and its Impact on the Community Law. The Amfiteatru Economic Journal, 15(33), 246-260.

Gongol, T. (2014). Contribution to the discussion on the notion of 'Alternative dispute resolutions'. European Offroads of Social Science, 5(1), 3-15.

Gongol, T. (2016). Judicial practice in selected countries in cases of legal liability of auction portals for the sale of counterfeits. Acta Academica Karviniensia, 16(4), 23-31. https://doi.org/10.25142/aak.2016.029.

Griffiths, A. (2008). A Law-and-Economic Perspective on Trade Marks. In: L. Bently, J. Davis, J. C. Ginsburg (ed). An Interdisciplinary Critique (pp. 241-267). Cambridge: Cambridge University Press. https://doi.org/10.1017/ CBO9780511495212.012.

Halvorson, T., Der, M. F., Foster, I., Savage, S., Saul, L. K., \& Voelker, G. M. (2015). From .Academy to .Zone: An Analysis of the New TLD Land Rush, In Proceedings of the 2015 ACM Conference on Internet Measurement Conference, (pp. 381-394). San Diego, CA: University of California. https://doi. org/10.1145/2815675.2815696.

Horáček, R., Čada, K., \& Hajn, P. (2017). Práva $k$ průmyslovému vlastnictví. 3rd ed. Praha: C. H. Beck.

Janis, M., \& Dinwoodie, G. (2007). Confusion Over Use: Contextualism in Trademark Law. lowa Law Review, 92, 1597-1667.

Jansa, L., Otevřel, P., Čermák, J., Mališ, P., Hostaš, P., Matějka M., \& Matejka, J. (2016). Internetové právo. Brno: Computer Press.

Janouch, V. (2014). Internetový marketing. 2nd ed. Brno: Computer Press.

Kleinbaum, D., Klein, M., \& Pryor, E., R. (2010). Logistic regression: a self-learning text. 3rd ed. New York, NY: Springer.

Klerman, D. (2016). Forum Selling and Domain-Name Disputes. Loyola University Chicago Law Journal, 48(2), 561-584.

Korczynski, M., Wullink, Tajalizadehkhoob, S., Moura, G. C., \& Hesselman, C. (2017). Statistical Analysis of DNS Abuse in gTLDs. ICANN. Retrieved July 23, 2019, from https://www.icann.org/en/ system/files/files/sadag-final-09aug17-en.pdf.

Lloyd, I. J. (2011). Information Technology Law. 6th ed. New York, NY: Oxford University Press.

Lukose, L. (2013). Consumer Protection vis a vis Trademark Law. International Journal on Consumer Law and Practise, 1(2013), 89-101.

Merges, R., Menell, P. S., \& Lemley M. A. (2012). Intellectual property in the new technological age. 6th ed. New York, NY: Wolters Kluwer.

Munková, J., Kindl, J., \& Svoboda, P. (2012). Soutěžní právo. 2nd ed. Prague: C. H. Beck.

Oullette, L. (2014). The Google Shortcut to Trademark Law. California Law Review, 102(2), 351-407. https://doi.org/10.2139/ssrn.2195989. 


\section{Marketing and Trade}

Otim, S., \& Grover, V. (2010). E-commerce: a brand name's curse. Electronic Markets, 20(2), 147-160. https://doi.org/10.1007/s12525010-0039-6.

Pelikánová, R. (2012). Ekonomické, právní a technické aspekty doménových jmen v globální perspektivě. Ostrava: Key Publishing.

Polčák, R. et al. (2018). Právo informačních technologií. Praha: Wolters Kluwer.

Saunders, K. M., \& Berger-Walliser, G. (2011). The Liability of Online Markets for Counterfeit Goods: A Comparative Analysis of Secondary Trademark Infringement in the United States and Europe. Northwestern Journal of International Law \& Business, 32(1), 37-92.

Senftleben, M. R. F. (2012). Keyword Advertising in Europe - How the Internet Challenges Recent Expansion of EU Trademark Protection. Connecticut Journal of International Law, 2012(27), 39-74.

Slováková, Z. (2006). Průmyslové vlastnictví. 2nd ed. Prague: LexisNexis.
Vissers, T., Wouter, J., \& Nikiforakis, N. (2015). Parking Sensors: Analyzing and Detecting Parked Domains. In Network and Distributed System Security Symposium. San Diego, CA: Internet Society. https://doi. org/10.14722/ndss.2015.23053.

Werra, J. (2016). Alternative Dispute Resolution in Cyberspace: The Need to Adopt Global ADR Mechanisms for Addressing the Challenges of Massive Online Micro-Justice. Swiss Review of International and European Law, 26(2), 289-306. https://doi.org/10.2139/ ssrn. 2783213 .

doc. Mgr. Tomáš Gongol, Ph.D. Silesian University in Opava School of Business Administration in Karvina Department of Business Economics and Management Czech Republic tomas.gongol@slu.cz 


\section{Abstract}

\section{TRADEMARK INFRINGEMENTS IN THE DOMAIN “.CZ”}

\section{Tomáš Gongol}

The aim of this article is to fill a gap in an area that has not yet been closely examined in the Czech Republic and the world: examining the level of trademark infringement in relation to the basic elements of the logical architecture of the Internet, namely domain names, resp. Websites that are published on them. The article aims to determine the actual state and create a methodology of rapid, and to some extent automated detection of the collision of rights connected to trademarks with domain names. Not only for the large scope of the investigated subject has it focused on the sector of the automotive industry in particular. Given the aim of the work, it answers questions whether the phenomenon of trademark infringement on the Internet is rather a minor issue, which concerns only a fraction of domain names and websites; whether the domains names, resp. websites violating the trademark rights share any similar characters; whether it is possible to automate the search process of finding trademark infringements or if there is a way of finding general rules that can be a valuable help in this process. The first part of the article describes the used methodology, sources of available data and the way the data were worked with. The next part deals in detail with input data that are relevant for this article. It describes the ways the data were obtained and the constraints that needed to be overcome doing so. Basic statistical parameters of the input data are also mentioned. The third part is focused on the important findings found in input data relating to Czech domain names and trademarks used on the Internet followed by detail examination of the Czech domain names for the sector of the automotive industry. By using the defined indicators of a collision (the characters) the results of the article show that the domain names on which the trademark infringement has been committed, share the same set of characters that can be tested automatically by a computer program.

Keywords: Alternative dispute resolution, domain name, logistic regression, trademark infringement.

JEL Classification: K24.

DOI: 10.15240/tul/001/2019-4-011. 